\title{
Diffusion Tensor Imaging Abnormalities in Cognitively Impaired Multiple Sclerosis Patients
}

\author{
Nadine Akbar, Nancy J. Lobaugh, Paul O'Connor, Linda Moradzadeh, \\ Christopher J.M. Scott, Anthony Feinstein
}

\begin{abstract}
Background: Cognitive impairment can add to the burden of disease in patients with multiple sclerosis (MS). The aim of this study was to assess the relative importance of diffusion tensor imaging (DTI) indices derived from normal appearing white matter (NAWM) and grey matter (NAGM) in determining cognitive dysfunction in MS patients. Methods: Sixty two MS patients [51 female, mean age $=41(\mathrm{sd}=9.6)$ years, median expanded disability status scale $(\mathrm{EDSS})=2.5$ ] meeting modified McDonald criteria for MS underwent neuropsychological testing using the Neuropsychological Screening Battery for MS (NSBMS) and magnetic resonance imaging (MRI, 1.5T GE) that included DTI sequences. Total $\mathrm{T}_{1}$ hypointense and $\mathrm{T}_{2}$ hyperintense lesion volumes were obtained using semi-automated software. Lesion volumes were subtracted from whole-brain parenchyma to obtain measures of NAWM and NAGM. Fractional anisotropy (FA) of NAWM and mean diffusivity (MD) of NAGM were obtained. Results: Cognitive impairment was present in 11 patients (18\%). These patients had higher EDSS scores, were less educated, and were more likely to have secondary progressive MS. They also had higher hypointense $(\mathrm{p}=0.001)$ and hyperintense $(\mathrm{p}=0.004)$ lesion volumes, greater NAWM atrophy $(\mathrm{p}=0.007)$, lower FA of total NAWM ( $\mathrm{p}=0.003)$, and higher MD of total NAGM ( $\mathrm{p}=0.015)$. Using a logistic regression analysis, and after controlling for demographic and disease-related differences between groups, FA of NAWM emerged as a significant predictor of cognitive impairment adding to the variance derived from lesion and atrophy data. Conclusion: This study underlies the important role of normal-appearing brain tissue in the pathogenesis of MS-related cognitive impairment.
\end{abstract}

RÉSUMÉ: Anomalies à l'imagerie en tenseur de diffusion chez les patients atteints de SP qui ont une atteinte cognitive. Contexte : L'atteinte cognitive peut augmenter le fardeau de la maladie chez les patients atteints de sclérose en plaques (SP). Le but de cette étude était d'évaluer l'importance relative d'indices à l'imagerie en tenseur de diffusion dérivés de la substance blanche et de la substance grise d'aspect normal (SBAN et SGAN) pour objectiver la dysfonction cognitive chez les patients atteints de SP. Méthodes : Soixante-deux patients atteints de SP (51 femmes; âge moyen 41 ans écart type 9,6; médiane EDSS 2,5) qui rencontraient les critères modifiés de McDonald pour la SP, ont subi une évaluation neuropsychologique au moyen de la Neuropsychological Screening Battery pour la SP et une imagerie par résonance magnétique (IRM, 1,5T GE) qui incluait des séquences DTI. Le volume total des lésions hypo intenses en T1 et hyper intenses en T2 a été évalué au moyen d'un logiciel semi-automatisé. Le volume des lésions était soustrait du parenchyme cérébral total pour obtenir les mesures de SBAN et de SGAN. L'anisotropie fractionnée (AF) de la SBAN et la diffusivité moyenne (DM) de la SGAN ont été évaluées. Résultats : Une atteinte cognitive était présente chez 11 patients (18\%). Ces patients avaient des scores plus élevés à l'EDSS, étaient moins instruits et étaient plus susceptibles d'avoir une SP secondairement progressive. Ils avaient également un volume de lésions hypo intenses et hyper intenses plus élevé ( $p=0,001$ et $p=0,004$ respectivement), plus d'atrophie de la SBAN ( $p=0,007)$, une AF de la SBAN totale plus basse $(\mathrm{p}=0,003)$ et une DM de la SGAN totale plus élevée $(\mathrm{p}=0,015)$. L'analyse de régression logistique, après ajustement pour les différences démographiques et les différences liées à la maladie entre les groupes, a montré que l'AF de la SBAN est un facteur de prédiction significatif de l'atteinte cognitive, ce qui ajoute à la variance dérivée des données sur les lésions et sur l'atrophie. Conclusion : Cette étude souligne le rôle important du tissu cérébral d'apparence normale dans la pathogenèse de l'atteinte cognitive liée à la SP.

Can. J. Neurol. Sci. 2010; 37: 608-614

Cognitive dysfunction is recognized as common sequelae of multiple sclerosis (MS) with the domains of episodic memory, working memory, speed of information processing, and attention most often affected. ${ }^{1}$ Cognitive impairment has a negative impact on quality of life, ${ }^{2}$ rehabilitation outcome, ${ }^{3}$ functional status and employment. ${ }^{4}$ While the associations between impaired cognition and disease-related variables such as disease duration $^{5}$ and disability ${ }^{6,7}$ are equivocal, more robust correlations have been reported with magnetic resonance imaging (MRI) indices. In particular brain atrophy has emerged as a more powerful predictor of cognitive impairment than lesion volume. ${ }^{8,9}$ More recently, data extracted from normal appearing grey (NAGM) and white (NAWM) matter using diffusion tensor imaging (DTI) or magnetic transfer imaging have been shown to

From the Department of Psychiatry (NA, NJL, LM, CJMS, AF), Sunnybrook Health Sciences Centre; University of Toronto (NA, NJL, POC, AF); St. Michael's Hospital (POC), Toronto, Ontario, Canada.

Received January 11, 2010. Final Revisions Submitted March 5, 2010.

Correspondence to: Nadine Akbar, Sunnybrook Health Sciences Centre, Department of Psychiatry, Room FG08, 2075 Bayview Avenue, Toronto, Ontario, M4N 3M5, Canada. 
correlate with cognitive impairment. ${ }^{10-15}$ However, these studies are few in number and it is unclear whether the indices obtained from normal appearing brain tissue (NABT) contribute anything beyond the lesion and atrophy data. For this reason, we undertook a DTI and cognitive study of patients with MS exploring the relative importance of lesions, atrophy, and NABT in the pathogenesis of cognitive impairment.

\section{METHODS}

\section{(i) Sample}

Sixty-two consecutive MS patients meeting modified McDonald criteria, ${ }^{16}$ and attending an out-patient MS clinic were enrolled. Patients were not paid to participate. Demographic data (age, education, marital status) and neurological data (expanded disability status scale [EDSS], duration of MS, disease course, and use of any disease-modifying drugs) were collected. Exclusion criteria were a history of drug/alcohol abuse, pre-MS psychiatric problems, traumatic brain injury with loss of consciousness, concurrent physical disease potentially affecting the central nervous system, and treatment with steroids in the three months prior to enrolment. Depression was measured using the Beck Depression Inventory-Fast Screen (BDI-FS) for medical patients, a scale that has been validated for use in MS. ${ }^{17}$

\section{(ii) Cognitive assessment}

All subjects completed the Neuropsychological Screening Battery for Multiple Sclerosis (NSBMS) ${ }^{18}$ prior to undergoing MRI scanning on the same day. The NSBMS comprises the following tests: (a) the Selective Reminding Test as an index of verbal memory, ${ }^{19}$ (b) the $7 / 24$ Spatial Recall Test as an index of non-verbal memory, ${ }^{20}$ (c) the Controlled Oral Word Association Test (COWAT) as a measure of lexical verbal fluency, ${ }^{21}$ and (d) the Paced Auditory Serial Addition Test (PASAT), ${ }^{22}$ as a marker of sustained attention and information processing speed.

In order to determine which subjects were cognitively impaired we followed the methodology specified by Rao in the NSBMS manual. ${ }^{18}$ Impairment was therefore defined as a score below the fifth percentile (based on established cut-offs from healthy individuals) on two or more of the four NSBMS measures. Our normative data were obtained from the published manual. Each MS patient's cognitive result was based on these normative data taking into account gender, age, and years of education.

\section{(iii) MR protocol}

All images were acquired on a $1.5 \mathrm{~T}$ Signa scanner (GE Medical Systems, Milwaukee, WI). Scanning sequences included a $\mathrm{T}_{1}$-weighted acquisition (axial three-dimensional spoiled gradient echo sequence with a 5-ms echo time [TE], 35$\mathrm{ms}$ repetition time [TR], 1 excitation, $35^{\circ}$ flip angle, $22 \times 16.5 \mathrm{~cm}$ field of view, $0.859 \times 0.859-\mathrm{mm}$ in-plane resolution, and a $1 \cdot 2$ to $1.4-\mathrm{mm}$ slice thickness) and proton density (PD) and $\mathrm{T}_{2}-$ weighted acquisitions (interleaved axial spin echo with TE of 30 and $80 \mathrm{~ms}, 3000 \mathrm{~ms}$ TR, 0.5 excitation, $22 \times 22-\mathrm{cm}$ field of view, $0.859 \times 0.859-\mathrm{mm}$ in-plane resolution, and a $3-\mathrm{mm}$ slice thickness).

An axial cardiac-gated DTI sequence was acquired with the following parameters: TR between 5000-8000 ms (depending on heart rate), TE $66 \mathrm{~ms}, 4$ excitations, 22 slices, resolution $1.88 \mathrm{x}$ $1.88 \times 4 \mathrm{~mm}$, along 11 gradient orientations, $\mathrm{B}=1000$, with two non-diffusion weighted baseline images $(B=0)$. A fast spin-echo $\mathrm{PD} / \mathrm{T}_{2}$ weighted sequence with TR/TE1/TE2 2500/24/85 msec to match the DTI slice prescription was acquired to facilitate registration with the $\mathrm{T}_{1}$-weighted image (see DTI analysis below).

\section{(iv) Tissue segmentation and atrophy measurements}

The $\mathrm{T}_{1}$-weighted image was segmented into grey matter, white matter, and cerebral spinal fluid (CSF) using an in-house automatic segmentation algorithm. ${ }^{23}$ Lesion volumes were subtracted from the white and grey matter tissue thereby leaving NAWM and NAGM. Atrophy of NAWM and NAGM were measured as the proportion of the total intracranial volume including CSF.

\section{(v) Lesion analysis}

Magnetic resonance images were processed on a Sun computer workstation (Palo Alto, CA) using the Analyze AVW 6.0 software package (Biomedical Imaging Resonance, Mayo Clinic, Rochester, MN). Hypointense lesions were identified on the $\mathrm{T}_{1}$-weighted images, and hyperintense lesions were defined on the $\mathrm{T}_{2} / \mathrm{PD}$-weighted datasets that had been co-registered to the $\mathrm{T}_{1}$-weighted images. Lesions $<3 \mathrm{~mm}$ in diameter in 3dimensional space were excluded from the analysis. Hyperintense lesions were defined using a semi-automated local thresholding technique in Analyze, and borders were adjusted manually as needed. Hypointense lesions were identified on the segmented $\mathrm{T}_{1}$-weighted images. All voxels that segmented as CSF on the $\mathrm{T}_{1}$-weighted image and were within a traced hyperintense lesion were relabeled as black holes. The measurement technique showed high intrarater (intraclass correlation coefficient $=0.98$ ) and interrater (intraclass correlation coefficient $=0.99$ ) reliability on a sample of 20 brains that were not part of the study sample. Total $\mathrm{T}_{1}$ hypointense and $\mathrm{T}_{2} / \mathrm{PD}$ hyperintense lesion volumes were obtained.

\section{(vi) DTI analysis}

The DTI data were corrected for motion and eddy-current distortions using the nonlinear registration tool provided in the FMRIB software library ("eddy_correct", http://www.fmrib.ox .ac.uk/fsl/). Fractional anisotropy (FA) and mean diffusivity (MD) maps were created from the corrected data using DTI studio (version 2.4.01). To generate whole-brain FA and MD data, the tissue segmentations were moved into DTI space. This was accomplished by nonlinear registration of the $\mathrm{T}_{1}$-weighted images with their first baseline DTI volume. For this dataset, the optimal pipeline consisted of a multistage affine registration of $\mathrm{T}_{1}$ to DTI and $\mathrm{T}_{2}$ to DTI using the spin-echo and fast spin-echo images as intermediate steps (AIR v. 5.25, Automated Image Registration, http://bishopw.loni.ucla.edu/AIR5/). ${ }^{24}$ Once the images were roughly aligned, the $\mathrm{T}_{2}$ and DTI images were fully registered using nonlinear registration (align_warp, 3-7 $7^{\text {th }}$ order, AIR 5.25). Finally, rotation matrices were combined to generate the nonlinear rotation required to move the $T_{1}$-weighted image and subsequent segmentation image into DTI space, which were resliced using nearest neighbor interpolation. The tissue 


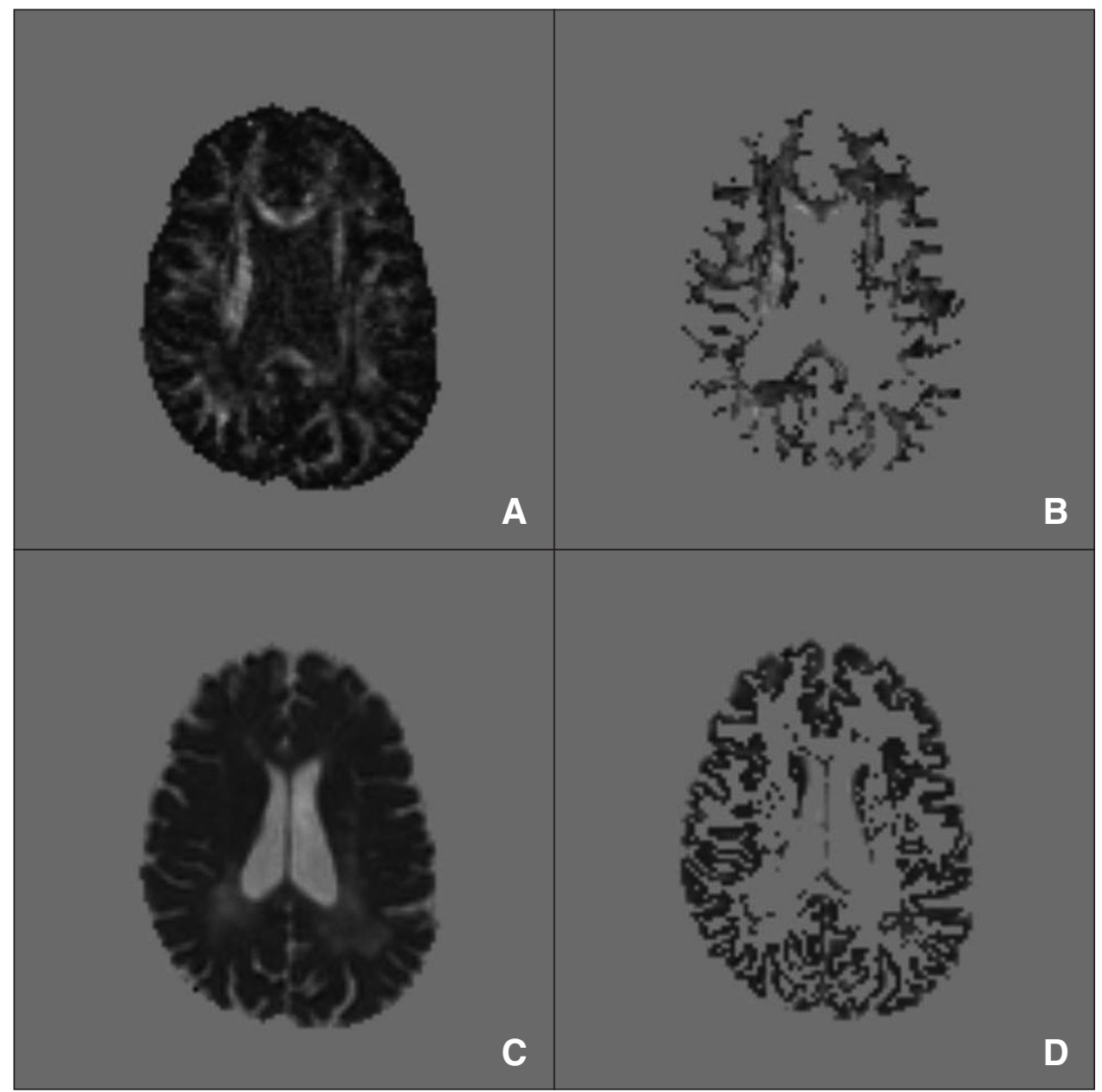

Figure: Stepwise process to derive FA and MD from NABT (a) FA image in DTI space, (b) FA normal appearing white matter (NAWM) image, (c) MD image in DTI space, (d) MD normal appearing grey matter (NAGM) image.

segmentation masks were combined with the FA and MD maps to obtain average values for NAWM and NAGM (see Figure).

\section{Statistical Analysis}

In the primary analysis, comparisons between subjects with and without cognitive impairment were undertaken for all demographic, neurological and imaging data. The latter included total hypointense and hyperintense lesion volume, NAWM and NAGM atrophy, FA of NAWM, and MD of NAGM. Statistical significance was set at $\mathrm{p}<.05$.

In the secondary analysis, predictors of cognitive impairment were sought using a logistic regression analysis. Variables entered into the analyses were those that differentiated the two groups in the primary analysis. Prior to entering the putative predictor variables into the regression analysis, correlations between them were explored. In the cases where two variables were significantly correlated $(r>.8)$, the variable with the more robust $t$-test was entered into the equation.
The regression analysis was modeled as follows: First, to control for the disease-related and demographic mismatch, EDSS, education and disease course were entered into the analysis. Thereafter we adopted a block entry design with each imaging variable entered sequentially according to their level of statistical significance derived from the primary analysis. At each step in the analysis an omnibus test of model coefficients was derived with a chi-square indicating whether the change in variance was significant or not.

\section{Ethics}

This study was approved by the Research Ethics Board at Sunnybrook Health Sciences Centre and St. Michael's Hospital, both affiliated with the University of Toronto. Written, informed consent was obtained from all subjects. 
Table 1: Demographic, disease-related, and psychiatric variables

\begin{tabular}{|c|c|c|c|c|}
\hline & $\begin{array}{l}\text { Not Cognitively } \\
\text { Impaired }(n=51)\end{array}$ & $\begin{array}{c}\text { Cognitively Impaired } \\
(n=11)\end{array}$ & $t$-test $/ \chi^{2}$ & $p$-value \\
\hline Age & $40.8(9.9)$ & $40.6(8.6)$ & $t=0.09$ & 0.93 \\
\hline Gender (F/M) & $40 / 11$ & $11 / 0$ & $\chi^{2}=2.9$ & $0.19^{\mathrm{a}}$ \\
\hline $\begin{array}{l}\text { Education } \\
\text { High-school } \\
\text { College or higher } \\
\end{array}$ & $\begin{array}{l}6 \\
45 \\
\end{array}$ & $\begin{array}{l}7 \\
4 \\
\end{array}$ & $x^{2}=14.7$ & ${ }^{* \star} 0.001^{\mathrm{a}}$ \\
\hline $\begin{array}{l}\text { Marital Status } \\
\text { Single } \\
\text { Married/ Common-Law } \\
\text { Divorced }\end{array}$ & $\begin{array}{l}11 \\
33 \\
7 \\
\end{array}$ & $\begin{array}{l}2 \\
9 \\
0 \\
\end{array}$ & $\chi^{2}=2.0$ & $0.60^{\mathrm{a}}$ \\
\hline Duration of MS symptoms (months) & 121.3(89.7) & $164.6(114.0)$ & $t=-1.4$ & 0.172 \\
\hline Time Since Diagnosis (months) & $89.0(72.6)$ & $120.8(52.2)$ & $t=-1.4$ & 0.174 \\
\hline $\begin{array}{l}\text { Disease Course } \\
\text { Relapsing-Remitting } \\
\text { Secondary Progressive } \\
\text { Primary Progressive }\end{array}$ & $\begin{array}{l}43 \\
6 \\
2 \\
\end{array}$ & $\begin{array}{l}6 \\
5 \\
0 \\
\end{array}$ & $\chi^{2}=7.2$ & ${ }^{*} 0.05^{\mathrm{a}}$ \\
\hline Any Disease Modifying Drugs (Y/N) & $28 / 23$ & $6 / 5$ & $\chi^{2}=0.0$ & 0.98 \\
\hline EDSS & $2.6(1.8)$ & $4.8(1.8)$ & $t=-3.6$ & ${ }^{* *} 0.001$ \\
\hline Beck Depression Inventory- Fast Screen & $7.2(4.5)$ & $9.6(3.4)$ & $t=-1.6$ & 0.108 \\
\hline
\end{tabular}

$*=\mathrm{p}<.05 ; * *=\mathrm{p}<.01 ;{ }^{\mathrm{a}}$ - using Fisher's exact test

\section{Results}

\section{(i) Sample characteristics}

The mean age of the sample was $40.7(s d=9 \cdot 6)$ years. Fifty one $(82 \cdot 3 \%)$ subjects were female, $13(21 \%)$ were single, 42 $(68 \%)$ married, and $7(11 \%)$ divorced. The mean duration since diagnosis was $94.6(\mathrm{sd}=70.1)$ months. Forty-nine $(79 \%)$ subjects had relapsing-remitting MS, 11 (18\%) had secondary progressive MS, and $2(3 \%)$ had primary progressive MS. Thirty-four (55\%) subjects were using disease modifying treatment. The median EDSS was 2.5. All subjects had, as a minimum education, completed high school.

(ii) Between-group demographic, neurological, and psychiatric comparisons

Eleven subjects (18\%) met the criteria for cognitive impairment. Comparisons between subjects with and without cognitive impairment are shown in Table 1. Subjects with cognitive impairment had lower education $(\mathrm{p}=.001)$, were more likely to have secondary progressive disease $(p=.05)$ and a higher EDSS score $(\mathrm{p}=.001)$. There was no difference between the two groups with respect to depression recorded by the BDI-FS, nor in their use of disease-modifying drugs (see Table 1). Group comparisons for the individual cognitive tests are shown in Table 2.

\section{(iii) Between-group comparisons on MRI variables}

Differences between groups on lesion, atrophy, and DTI measures are shown in Table 3. Patients with cognitive impairment had larger hypointense and hyperintense lesion volumes, greater NAWM atrophy, lower NAWM FA and higher NAGM MD. There was no difference in NAGM atrophy.

\section{(iv) Predictors of cognitive impairment}

A logistic regression analysis was used to investigate predictors of cognitive impairment. The disease and demographic variables that differentiated the two groups were first entered into the model. Education, EDSS, and disease course were able to explain $46.4 \%$ of the variance $\left(R^{2}=.464\right.$; percentage correctly classified $85.5, \chi^{2}=20.50, p<.001$ ). Lesion and atrophy data were then entered into the model sequentially according to their level of statistical significance derived from the primary analysis. Hypointense lesion volume raised the variance percentage to $54.8 \%\left(R^{2}=.548\right.$, percentage correctly classified 91.9). An omnibus test of model coefficients revealed that this change was statistically significant $\left(\chi^{2}=4.57, p=.033\right)$. Adding hyperintense lesion volume, followed by NAWM atrophy did not significantly change the result $\left(R^{2}=.548\right.$, percentage correctly classified $91.9, \chi^{2}=0, p=.996$, and $R^{2}=.550$, 
Table 2: Cognitive test performance of patients with $(n=11)$ and without $(n=51)$ cognitive impairment based on the four cognitive parameters specified by Rao $^{18}$ for the Neuropsychological Screening Battery for MS (NSBMS)

\begin{tabular}{|c|c|c|c|c|c|c|}
\hline & \multicolumn{2}{|c|}{ Not Cognitively Impaired $(n=51)$} & \multicolumn{2}{|c|}{ Cognitively Impaired $(n=11)$} & \multirow{2}{*}{$\begin{array}{l}t \text {-test/ Mann-Whitney } \\
\text { U-test }\end{array}$} & \multirow{2}{*}{$p$-value } \\
\hline & Mean & SD & Mean & SD & & \\
\hline $\begin{array}{l}\text { Selective Reminding Test- Consistent Long-Term } \\
\text { Retrieval }\end{array}$ & 39.1 & 15.1 & 21.6 & 18.6 & $t=3.3$ & $.001^{\star *}$ \\
\hline 7/24 Spatial Recall Test- Total Recall (Trials 1-5) & 32.3 & 2.9 & 25.5 & 7.6 & $U=127.0$ & $.004^{* *}$ \\
\hline PASAT - 2 seconds Total Correct & 34.1 & 8.6 & 15.8 & 8.2 & $t=6.4$ & $<.001^{* *}$ \\
\hline COWAT Total Correct Responses & 40.2 & 10.0 & 21.0 & 10.4 & $t=5.7$ & $<.001^{* *}$ \\
\hline
\end{tabular}

$* *=\mathrm{p}<.01 ;$ PASAT $=$ Paced auditory serial addition test; COWAT $=$ Controlled oral word association test.

percentage correctly classified 90.3, $\chi^{2}=.110, \quad p=.740$, respectively). When DTI data were added to the model FA of NAWM raised the variance from $55 \%$ to $65 \%\left(R^{2}=.650\right.$, percentage correctly classified 93.5), a statistically significant change $\left(\chi^{2}=5.96, p=.015\right)$. Thereafter, adding MD of NAGM did not raise the variance percentage $\left(R^{2}=.651\right.$, percentage correctly classified 93.5, $\left.\chi^{2}=.031, p=.861\right)$.

\section{Discussion}

This study confirms the previously reported association between cognitive impairment on the one hand and lesion volume (hypointense and hyperintense) and atrophy of NAWM on the other. Of note, however, is that fractional anisotropy derived from NAWM added significantly to the hypointense lesion data in explaining the presence of cognitive impairment.

Before discussing the significance of these findings some comment on our sample is required. This is necessary because the percentage of cognitively impaired patients in our study was low relative to much, but not all, published data. We recruited our subjects from a consecutive sample of community based patients attending their yearly clinic appointment. In a landmark publication, Rao et $\mathrm{al}^{1}$ reported that approximately $40 \%$ of community based patients had cognitive dysfunction, a figure subsequently replicated. ${ }^{25}$ However, a recent study from Italy of 550 MS patients found only $20 \%$ of subjects were cognitively impaired, albeit based on an unusual cut-off point of 1 SD below normative data. ${ }^{7}$ While direct comparisons are often problematic, what is notable about this study is that the subjects all had relapsing-remitting $\mathrm{MS}$ and mild disability, a profile that overlaps with our sample composition. However, a subsequent re-analysis of the Italian data using a different, more conventional threshold for determining cognitive impairment raised the percentage of patients deemed impaired ${ }^{26}$ We do not have this degree of flexibility given that we have closely

Table 3: MRI differences between patients with $(n=11)$ and without $(n=51)$ cognitive impairment

\begin{tabular}{|c|c|c|c|c|c|c|c|c|}
\hline & \multicolumn{3}{|c|}{ Not Cognitively Impaired $(n=51)$} & \multicolumn{3}{|c|}{ Cognitively Impaired $(n=11)$} & \multirow{2}{*}{$\begin{array}{c}t \text {-test/ Mann- } \\
\text { Whitney U-test }\end{array}$} & \multirow[t]{2}{*}{$p$-value } \\
\hline & Mean & SD & $95 \% \mathrm{Cl}$ & Mean & SD & $95 \% \mathrm{Cl}$ & & \\
\hline Hypointense lesion volume $\left(\mathrm{cm}^{3}\right)$ & 0.24 & 0.45 & $0.12-0.37$ & 1.49 & 1.32 & $0.60-2.38$ & $U=-3.21$ & $.001^{* *}$ \\
\hline Hyperintense lesion volume $\left(\mathrm{cm}^{3}\right)$ & 7.97 & 8.98 & $5.45-10.5$ & 17.4 & 9.92 & $10.7-24.1$ & $U=-2.88$ & $.004^{\star *}$ \\
\hline Normal appearing white matter (NAWM) atrophy ${ }^{a}$ & .333 & .039 & $.322-.344$ & .295 & .050 & $.261-.328$ & $t=2.77$ & $.007^{* *}$ \\
\hline Normal appearing grey matter (NAGM) atrophy ${ }^{a}$ & .478 & .022 & $.471-.484$ & .470 & .026 & $.453-.487$ & $t=1.02$ & .314 \\
\hline Fractional Anisotropy (FA) of NAWM & .265 & .014 & $.261-.268$ & .251 & .012 & $.243-.259$ & $t=3.05$ & $.003^{\star *}$ \\
\hline Mean Diffusivity (MD) of NAGM $\left(\mu \mathrm{m}^{2} \mathrm{~ms}^{-1}\right)$ & 2.91 & .18 & $2.86-2.96$ & 3.06 & .18 & $2.94-3.18$ & $t=-2.50$ & $.015^{\star}$ \\
\hline
\end{tabular}

$*=\mathrm{p}<.05 ; * *=\mathrm{p}<.01 ; \mathrm{a}-$ represented as proportion of total intracranial volume 
followed the guidelines for determining global cognitive impairment as specified by Rao in the NSBMS manual. ${ }^{18}$ As such, our figure of $18 \%$ is less amenable to change. This leads us to conclude that our sample had relatively fewer cognitively impaired patients than anticipated. In part this may reflect the fact that our sample was highly educated with $79 \%$ having a college education or higher. Furthermore, it is unlikely that our lower prevalence is due to the "Will Rogers Phenomenon" reported in other areas of MS research ${ }^{27}$ as recent studies using newer diagnostic criteria still arrive at figures for cognitive impairment in the region of $40 \%$.

The link between cognitive dysfunction and imaging indices derived from NABT can be traced to the early MRI literature, in particular measurement of $\mathrm{T}_{1}$ relaxation times. ${ }^{28}$ This observation has been supported by data obtained from positron emission tomography ${ }^{29}$ and MR spectroscopy. ${ }^{30}$ More recently, the emphasis has shifted to MRI derived indices of NABT, namely DTI and magnetic transfer imaging, with promising results, ${ }^{11-15}$ although not all studies were able to demonstrate significant DTI differences between cognitively impaired and intact subjects. ${ }^{10}$ Here our results replicate the results of a diffusion weighted imaging (DWI) study, ${ }^{31}$ a technique considered less sensitive than DTI in detecting higher-order components of water diffusion in tissue. The sensitivity of DTI as a marker of cerebral integrity is further underscored by a study involving patients with benign MS, some of whom were cognitively impaired. ${ }^{32}$ When this subgroup of impaired subjects was compared to patients with secondary progressive MS, no differences were found with respect to $\mathrm{T}_{2}$ lesion volume, atrophy, and DTI measurements of normal appearing white and grey matter.

Our most notable finding was that DTI derived data boosted the variance when it came to explaining cognitive problems. Two DTI indices were obtained, fractional anisotropy and mean diffusivity. Fractional anisotropy provides a measure of the longitudinal diffusion of water along fibres and is commonly referred to as a marker of the structural integrity of white matter tracts, whereas MD gives a measure of water diffusion that is less influenced by the inherent directionality in the underlying tissue microstructure. Both may be affected independently of lesions as demonstrated by Dineen et $\mathrm{al}^{11}$ who found that areas of FA damage within white matter tracts did not overlap well with lesion distribution probability maps. Our results provide further support for this by illustrating that FA of NAWM in particular added significantly and independently to the hypointense lesion volume in accounting for the variance in cognitive dysfunction. This finding also extends results from the earlier DWI study ${ }^{31}$ which revealed that entropy, a measure of the degree of disorder of diffusion within brain tissue, added to the grey matter fraction in accounting for unique variance in performance on a single cognitive measure, the Symbol Digit Modalities Test. These authors, however, did not assess the independent contribution of DWI to overall cognitive impairment.

We did not find an association between atrophy of NAGM and cognitive abnormalities, a result at odds with recent imaging data. ${ }^{9,33-35}$ This was counterbalanced by our result showing that MD of NAGM differentiated between cognitively impaired and intact groups, possibly by providing an indicator of cortical demyelination or retrograde degeneration of grey matter neurons secondary to axonal damage. While this cerebral marker did not emerge as an independent predictor of cognition we do not discount it based on our data given that the small sample size of the cognitively impaired group may have compromised this result.

Our study is not without limitations, the first being the absence of scan-rescan data attesting to potential variability in data acquisition. Second, the small number of cognitively impaired patients introduces a note of caution when it comes to interpreting our results and could explain why age did not differ between our patients with RRMS and SPMS. This suggests that our cognitively impaired group could be atypical, a factor that may also underlie our gray matter atrophy findings. Finally, our cognitive battery was limited and did not contain a sensitive cognitive measure such as the Symbol Digit Modalities Test which could have led to a more robust correlate with NAGM emerging. Of note, however, is that the battery we used, namely the NSBMS, has good proven validity in MS populations with a $71 \%$ sensitivity and a $94 \%$ specificity. ${ }^{1}$ Furthermore the manual provides normative data according to relevant demographics (age, education, gender) which makes it a practical cognitive tool for use with MS patients.

\section{ConClusions}

In summary, our findings illustrate that lesions and atrophy tell only part of the story when it comes to explaining cognitive dysfunction. Data extracted from NABT reveals that more pervasive and subtle markers of a disordered anatomy contribute independently to cognitive dysfunction. From this we can conclude that even in a sample with mild to moderate physical disability it is important to look beyond the more conventional markers of brain pathology for clues as to the origins of cognitive compromise.

\section{ACKNOWLEDGEMENTS} Canada.

This study was funded by the Multiple Sclerosis Society of

Dr. Feinstein has received honoraria from Merck Serono, Bayer HealthCare Pharmaceuticals and Teva. Dr. O'Connor has received consulting fees and/or research support for MS trials from Bayer, Biogen Idec, BioMS, Cognosci, Daiichi Sankyo, EMD Serono, Genentech, Genmab, Novartis, Roche, Sanofi Aventis, and Teva.

\section{REFERENCES}

1. Rao SM, Leo GJ, Bernardin L, et al. Cognitive dysfunction in multiple sclerosis. I. Frequency, patterns, and prediction. Neurology. 1991;41(5):685-91.

2. Benito-León J, Morales JM, Rivera-Navarro J. Health-related quality of life and its relationship to cognitive and emotional functioning in multiple sclerosis patients. Eur J Neurol. 2002;9 (5):497-502.

3. Langdon DW, Thompson AJ. Multiple sclerosis: a preliminary study of selected variables affecting rehabilitation outcome. Mult Scler. 1999;5(2):94-100.

4. Rao SM, Leo GJ, Ellington L, et al. Cognitive dysfunction in multiple sclerosis. II. Impact on employment and social functioning. Neurology. 1991;41(5):692-6.

5. Beatty WW, Goodkin DE, Hertsgaard D, et al. Clinical and demographic predictors of cognitive performance in multiple sclerosis. Do diagnostic type, disease duration, and disability matter? Arch Neurol. 1990;47(3):305-8. 
6. Ron MA, Callanan MM, Warrington EK. Cognitive abnormalities in multiple sclerosis: a psychometric and MRI study. Psychol Med. 1991;21(1):59-68.

7. Patti F, Amato MP, Trojano M, et al. Cognitive impairment and its relation with disease measures in mildly disabled patients with relapsing-remitting multiple sclerosis: baseline results from the Cognitive Impairment in Multiple Sclerosis (COGIMUS) study. Mult Scler. 2009;15(7):779-88.

8. Benedict RH, Weinstock-Guttman B, Fishman I, et al. Prediction of neuropsychological impairment in multiple sclerosis: comparison of conventional magnetic resonance imaging measures of atrophy and lesion burden. Arch Neurol. 2004;61 (2):226-30.

9. Sanfilipo MP, Benedict RH, Weinstock-Guttman B, et al. Gray and white matter brain atrophy and neuropsychological impairment in multiple sclerosis. Neurology. 2006;66(5):685-92.

10. Rovaris M, Iannucci G, Falautano M, et al. Cognitive dysfunction in patients with mildly disabling relapsing-remitting multiple sclerosis: an exploratory study with diffusion tensor MR imaging. J Neurol Sci. 2002;195(2):103-9.

11. Dineen RA, Vilisaar J, Hlinka J, et al. Disconnection as a mechanism for cognitive dysfunction in multiple sclerosis. Brain. 2009;132:239-49.

12. Warlop NP, Achten E, Fieremans E, et al. Transverse diffusivity of cerebral parenchyma predicts visual tracking performance in relapsing-remitting multiple sclerosis. Brain Cogn. 2009;71(3): 410-5.

13. Rovaris M, Filippi M, Minicucci L, et al. Cortical/subcortical disease burden and cognitive impairment in patients with multiple sclerosis. Am J Neuroradiol. 2000;21(2):402-8.

14. Filippi M, Tortorella C, Rovaris M, et al. Changes in the normal appearing brain tissue and cognitive impairment in multiple sclerosis. J Neurol Neurosurg Psychiatry. 2000;68(2):157-61.

15. Cox D, Pelletier D, Genain C, et al. The unique impact of changes in normal appearing brain tissue on cognitive dysfunction in secondary progressive multiple sclerosis patients. Mult Scler. 2004;10(6):626-9.

16. Polman $\mathrm{CH}$, Reingold SC, Edan G, et al. Diagnostic criteria for multiple sclerosis: 2005 revisions to the "McDonald Criteria". Ann Neurol. 2005;58(6):840-6.

17. Benedict RHB, Fishman I, McClellan MM, et al. Validity of the Beck Depression Inventory- Fast Screen in multiple sclerosis. Mult Scler. 2003; 9(4):393-6.

18. Rao SM. Neuropsychological screening battery for multiple sclerosis manual. Department of Neurology, Medical College of Wisconsin; 1991.

19. Buschke H, Fuld PA. Evaluating storage, retention, and retrieval in disordered memory and learning. Neurology. 1974;24:1019-25.

20. Rao SM, Hammeke TA, McQuillen MP, et al. Memory disturbance in chronic progressive multiple sclerosis. Arch Neurol. 1984;41: $625-31$.
21. Benton AL, Hamsher KD. Multilingual aphasia examination. University of Iowa, Iowa City, IA; 1976.

22. Gronwall DMA. Paced auditory serial-addition task: a measure of recovery from concussion. Percept Mot Skills. 1977;44:367-73.

23. Kovacevic N, Lobaugh NJ, Bronskill MJ, et al. A robust method for extraction and automatic segmentation of brain images. Neuroimage. 2002;17:1087-1100.

24. Woods RP, Grafton ST, Watson JDG, et al. Automated image registration: II. Intersubject validation of linear and nonlinear models. J Comput Assist Tomogr. 1998;22:153-65.

25. Amato MP, Zipoli V, Portaccio E. Multiple sclerosis-related cognitive changes: a review of cross-sectional and longitudinal studies. J Neurol Sci. 2006;245(1-2):41-6.

26. Benedict RH. Standards for sample composition and impairment classification in neuropsychological studies of multiple sclerosis. Mult Scler. 2009;15(7):777-8.

27. Sormani MP, Tintore M, Rovaris M, et al. Will Rogers phenomenon in multiple sclerosis. Ann Neurol. 2008; 64(4):428-33.

28. Feinstein A, Kartsounis LD, Miller DH, et al. Clinically isolated lesions of the type seen in multiple sclerosis: a cognitive, psychiatric, and MRI follow up study. J Neurol Neurosurg Psychiatry. 1992;55(10):869-76.

29. Blinkenberg M, Rune $\mathrm{K}$, Jensen $\mathrm{CV}$, et al. Cortical cerebral metabolism correlates with MRI lesion load and cognitive dysfunction in MS. Neurology. 2000;54(3):558-64.

30. Foong J, Rozewicz L, Davie CA, et al. Correlates of executive function in multiple sclerosis: the use of magnetic resonance spectroscopy as an index of focal pathology. J Neuropsychiatry Clin Neurosci. 1999;11(1):45-50.

31. Benedict RH, Bruce J, Dwyer MG, et al. Diffusion-weighted imaging predicts cognitive impairment in multiple sclerosis. Mult Scler. 2007;13(6):722-30.

32. Rovaris M, Riccitelli G, Judica E, et al. Cognitive impairment and structural brain damage in benign multiple sclerosis. Neurology. 2008;71:1521-6.

33. Calabrese M, Agosta F, Rinaldi F, et al. Cortical lesions and atrophy associated with cognitive impairment in relapsing-remitting multiple sclerosis. Arch Neurol. 2009;66(9):1144-50.

34. Amato MP, Bartolozzi ML, Zipoli V, et al. Neocortical volume decrease in relapsing-remitting MS patients with mild cognitive impairment. Neurology. 2004;63(1):89-93.

35. Tekok-Kilic A, Benedict RH, Weinstock-Guttman B, et al. Independent contributions of cortical gray matter atrophy and ventricle enlargement for predicting neuropsychological impairment in multiple sclerosis. Neuroimage. 2007;36(4): 1294-300. 